\title{
水稲群落上での二酸化炭素のフラックスと勾配の関係
}

猪原幸子*・岩田 徹**・三浦健志**・大藤明克***・樋口宣寿***・大滝英治**

$$
\left(\begin{array}{c}
* \text { 岡山大学大学院自然科学研究科 } \\
* * \text { 岡山大学環境理工学部 } \\
* * * \text { (財) 日本気象協会関西支社 }
\end{array}\right)
$$

\section{The Flux-Gradient Relationship of Carbon Dioxide over a Paddy Field}

\author{
Sachiko Inohara*, Toru IwatA**, Takeshi Mivra**, Akinori ОнтоU***, \\ $\left(\begin{array}{c}\text { Yoshihisa HIGUCHI** and Eiji OHтAKI** } \\ * \text { Graduate School of Natural Science and Technology, Okayama University, Okayama, 700-8530 Japan } \\ \text { ** Faculty of Environmental Science and Technology, Okayama University, Okayama, 700-8530 Japan } \\ * * * \text { Japan Weather Association Kansai Regional Office, Osaka, 537-0011 Japan }\end{array}\right)$
}

\begin{abstract}
To elucidate the seasonal and inter-annual variation of $\mathrm{CO}_{2}$ exchanges between the atmosphere and paddy field, the $\mathrm{CO}_{2}$ flux has been measured by the eddy correlation technique at the experimental farm of the Agricultural Faculty, Okayama University, since December in 1998. The $\mathrm{CO}_{2}$ sensor, however, does not work under rainy conditions. The improved aerodynamic technique was developed and used to fill the gap in the eddy flux data. This technique gave reasonable $\mathrm{CO}_{2}$ fluxes even on rainy days. The reliability of the technique was also confirmed by comparing $\mathrm{CO}_{2}$ fluxes with those measured by the eddy correlation technique.
\end{abstract}

Key words: Aerodynamic technique, Carbon dioxide, Eddy correlation technique, Flux-gradient relationship.

キーワード : 渦相関法, 空気力学的傾度法, 二酸化炭素, 無次元勾配

\section{1.はじめに}

近年, 大気中の二酸化炭素濃度の増加之地球温暖化問 題を背景として, 各種陸上生態系-大気間の二酸化炭素, 水蒸気, 熱フラックスの長期的観測に基づいた炭素収 支, 水収支, 熱収支の正確な把握が求められている (Yamamoto, 1999; Harazono et al., 2003)。われわれ は, 1998 年 12 月から日本の一般的な耕作形態をとって いる岡山大学農学部附属農場を利用して, 耕作地に掞け る二酸化炭素と水蒸気フラックスの通年的な特徽を把握 するための観測を実施している。フラックス観測は，主 として渦相関法に基づいているが, センサーの動作不安 定による欠測が避けられない。特に，降雨時にはオープ ンパス型の二酸化炭素・水蒸気センサーは作動不能であ る。長期観測では, 測定センサーの保守管理に留意する と共に, 複数の観測手法を併用させておき, デー夕の品 質確保と欠測值の補てんに備えておくことが大切であ
る。 二酸化炭素変動計が開発されて以来 (Ohtaki and Matsui, 1982; Ohtaki, 1984), 二酸化炭素フラックス が渦相関法で直接測定できるようになってきた。この渦 相関法によるフラックスデータと 2 高度間の二酸化炭 素密度差のデータを組み合わせると, 二酸化炭素の無次 元勾配量が評価できる (Ohtaki， 1985; Monji et al., 2002; Monji, 2003)。この無次元勾配の安定度依存の関 数形を確立することができれば, 二酸化炭素の 2 高度間 の密度差の情報と組み合わせて傾度法によってフラック スを推定することができる (Harazono et al., 1996; Miyata, 2001)。われわれは, 渦相関法による欠測を少 なくするために，この新しい考えによる傾度法を併用す ることを考え, 2002 年夏季に集中観測を実施した。二酸 化炭素のフラックスと勾配の関係に基づいた傾度法の実 用性を検討したので報告する。 


\section{2. 二酸化炭素フラックスに関する基本式}

渦相関法による二酸化炭素フラックスは, 次式で表さ れる (Webb et al., 1980)。

$$
\overline{w c}=\overline{w^{\prime} c^{\prime}}+\bar{w} \bar{c}
$$

ここで, $w$ は鉛直風速成分， $c$ は二酸化炭素密度である。 一は時間平均を示し, 'は平均からの偏差である。Webb et al. (1980) は, 乾燥空気の鉛直フラックスはゼロと仮 定して，（1）式の $\bar{w}$ を求めた。

$$
\overline{w \rho_{\mathrm{a}}}=\overline{w^{\prime} \rho_{\mathrm{a}}{ }^{\prime}}+\bar{w} \overline{\rho_{\mathrm{a}}}=0
$$

ここで， $\rho_{\mathrm{a}}$ は乾燥空気の密度である。鉛直風速成分 $\bar{w}$ 測定できるパラメーターで置き換え，（1）式に代入す る。

$$
\begin{aligned}
\overline{w c}= & \overline{w^{\prime} c^{\prime}}-\left(\bar{c} / \overline{\rho_{\mathrm{a}}}\right) \overline{w^{\prime} \rho_{\mathrm{a}}{ }^{\prime}} \\
= & \overline{w^{\prime} c^{\prime}}+A \overline{w^{\prime} q^{\prime}}+B \overline{w^{\prime} T^{\prime}} \\
& 1 \text { 項 } \quad 2 \text { 項 } 3 \text { 項 }
\end{aligned}
$$

( $\left.3^{\prime}\right)$ 式の右辺各項の意味は次の通りである。

1 項: 渦相関センサーによって測定した生の二酸化炭素

フラックス。二酸化炭素密度と鉛直風速の乱流变動成 分から求める。本報では $F_{\mathrm{c}}($ eddy) と表す。

2 項: 潜熱フラックスが寄与する二酸化炭素フラック ス。係数は, $A=\left(m_{\mathrm{a}} / m_{\mathrm{q}}\right)\left(\overline{\mathrm{c}} / \overline{\rho_{\mathrm{a}}}\right)$ である。ただし, $m_{\mathrm{a}}$

と $m_{\mathrm{q}}$ は乾燥空気と水蒸気の分子量である。

3 項: 顕熱フラックスが寄与する二酸化炭素フラック

ス。係数は, $B=\left[1+\left(\bar{q} / \overline{\rho_{\mathrm{a}}}\right)\left(m_{\mathrm{a}} / m_{\mathrm{q}}\right)\right](\overline{\boldsymbol{c}} / \overline{\boldsymbol{T}})$ である。 ただし, $q$ と $T$ は水蒸気密度と絶対温度である。

$\left(3^{\prime}\right)$ 式の右辺第 1 項は乱流变動成分から求めたフ ラックスであり, 大気中の二酸化炭素密度差に関係した 従来の傾度法によるフラックスに相当している（例え ば, Monji, 2003)。第 2 項と第 3 項は大気中の二酸化炭 素密度差とは直接的に結びついたものではなく, 乾燥空 気のフラックスがゼロという制約条件から派生する二酸 化炭素フラックスである（Webb et al., 1980）。言い換 えると, 第 2 項と第 3 項は気温が鉛直勾配を有している とき, 乾燥空気の鉛直密度差が存在しそのフラックスを ゼロにするために空気塊の上向き，下向きの移動量が異 なることに起因する二酸化炭素フラックス $(\bar{w} \bar{c})$ であ り, 大気中の二酸化炭素密度が高さと共に変わらない等 密度場であってあ創出されるフラックス項である。

次に, 渦相関法で欠測となった二酸化炭素フラックス を, 二酸化炭素の無次元勾配 $\phi_{\mathrm{c}}$ を利用して補完する方 法を述べる。二酸化炭素の無次元勾配 $\phi_{\mathrm{c}}$ は, 次の (4) 式 で定義されている（Ohtaki, 1985; Monji et al., 2002; Monji, 2003)。

$$
\begin{aligned}
\phi_{\mathrm{c}} & =-\left(k z u_{*} / \overline{w^{\prime} c^{\prime}}\right) \mathrm{d} \bar{c} / \mathrm{d} z \\
& =k u_{*}\left(\overline{c_{1}}-\overline{c_{2}}\right) /\left[\overline{w^{\prime} c^{\prime}} \ln \left(z_{2} / z_{1}\right)\right]
\end{aligned}
$$

二酸化炭素のフラックス項, $\overline{w^{\prime} c^{\prime}}$ は $\left(3^{\prime}\right)$ 式の右辺第 1 項の $\overline{w^{\prime} c^{\prime}}$ と同じあのである。また, $k$ はカルマン定数 (0.4), $u_{*}$ は摩擦速度, $z$ は測定高度である。この測定 高度 $z$ は植物群落の零面変位 $d$ を考慮して $z-d$ と記す ベきであるが，簡単のために本論文では $z$ としている。 また, 添え字 1 と 2 は測定高度で, 本研究では, 地上 $1.3 \mathrm{~m}$ と $3.9 \mathrm{~m}$ を意味している。 $\left(4^{\prime}\right)$ 式を求めるには, 二酸化炭素密度の鉛直分布が対数則に従うと仮定し, $\mathrm{d} \bar{c} / \mathrm{d} z=\left(\overline{c_{2}}-\overline{c_{1}}\right) /\left[z \ln \left(z_{2} / z_{1}\right)\right], z=\left(z_{1} z_{2}\right)^{1 / 2}$ としている (Monji et al., 2002)。Dyer and Hicks（1970）は, 大 気成層の不安定度が強くなってもこの微係数近似の誤差 は $0.5 \%$ 以下であると報告している。

渦相関法で $u_{*}$ と二酸化炭素フラックス $\overline{w^{\prime} c^{\prime}} ， 2$ 高度 に拉ける二酸化炭素密度 $\overline{c_{1}}$ と $\overline{c_{2}}$ を測定すれば, $\left(4^{\prime}\right)$ 式 によって $\phi_{\mathrm{c}}$ を求めることができる。むし, いろいろな気 象条件下で $\phi_{\mathrm{c}}$ を求め, その安定度依存の関数形が確定 できれば，逆に考えて， $u_{*}$ と $\phi_{\mathrm{c}}$ 関数， 2 高度の二酸化炭 素密度 $\overline{c_{1}}$ と $\overline{c_{2}}$ の情報から二酸化炭素の乱流变動による フラックス $\left(\overline{w^{\prime} c^{\prime}}\right)$ を推定することができる。二酸化炭 素密度差の情報を利用するので, この方法で得られる二 酸化炭素フラックスを $F_{\mathrm{c}}(\mathrm{aero})$ と書く。実際には, $F_{\mathrm{c}}($ aero) が高さによらないとして,（4）式を積分して得 た次の関係式を利用して $F_{\mathrm{c}}($ aero $)$ を求めることにな る。

$$
F_{\mathrm{c}}(\text { aero })=k u_{*}\left(\overline{c_{2}}-\overline{c_{1}}\right) / f(\zeta)
$$

ここで, $\zeta=z / L\left(=-k z(g / \bar{T}) \overline{w^{\prime} T^{\prime}} / u_{*}{ }^{3}\right)$ は MoninObukhov の安定度パラメーターであり, $g$ は重力の加 速度, $T$ は温度である。また, 後述するように, $f(\zeta)$ は $\phi_{\mathrm{c}}$ の安定度依存性によって決まる関数である。

\section{3. 観測場所とデー夕選抜}

\section{1 観 測 場 所}

観測は岡山県玉野市八浜町の児島湾干拓地にある八浜 農場 $\left(34^{\circ} 32^{\prime} \mathrm{N}, 133^{\circ} 56^{\prime} \mathrm{E}\right)$ の水稲圃場で実施した (Fig. 1)。八浜農場は約 $300 \mathrm{~m} \times 300 \mathrm{~m}$ の広さを有して おり, 周辺屯同様の農耕地である。主風向に対する最短 の吹走距離は約 $500 \mathrm{~m}$ である。解析対象期間である 2002 年 9 月の水稲の平均草高は $1 \mathrm{~m}$ であった。地上 $1.65 \mathrm{~m}$ に設置した超音波風速温度計（Kaijo Co., DA600-3T）で風速変動と気温変動を, $\mathrm{CO}_{2} / \mathrm{H}_{2} \mathrm{O}$ アナライ ザー（Li-Cor Ltd., LI-7500）で二酸化炭素密度変動と 水蒸気密度变動を測定した。これらの測定器の信号を $10 \mathrm{~Hz}$ でサンプリングし，ハードディスクに記録した。 デー夕解析時には,（1）風速計の傾斜補正と風向方向へ の座標変換，（2）横風補正，（3）直線回帰によるトレン ド除去，(4) 二酸化炭素フラックスは Webb et al. (1980) 


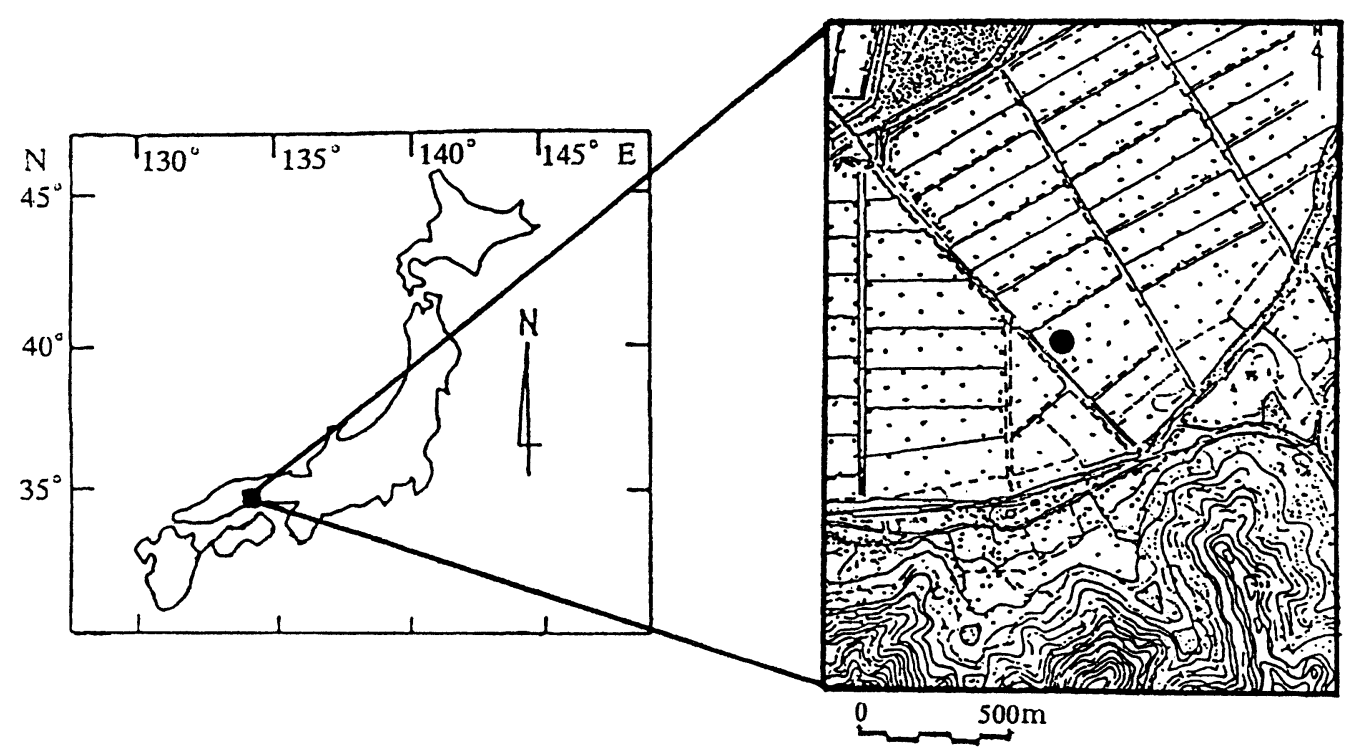

Fig. 1. Map of Japan showing the location of measuring site (@).

補正項の計算, を行った。フラックス等の統計量は 30 分間の平均值として算出した。

渦相関法センサーから約 $5 \mathrm{~m}$ 離札た地点に観測塔を 立て, 地上 $1.3 \mathrm{~m}$ と $3.9 \mathrm{~m}$ に抢ける温度と相対湿度を Vaisala 製のセンサー（HMP45A）で測定し，二酸化炭 素密度を高分解能 $\mathrm{CO}_{2}$ アナライザー (Li-Cor Co. Ltd., LI-6252) で測定した。LI-6252 は絶対值測定モードで 使用した。2 高度から試料空気を吸引し, 過塩素酸マグ ネシウムを充填したカラム（長さ約 $0.15 \mathrm{~m}$ ) を通過させ て除湿する。過塩素酸マグネシウムの約半分が湿った状 態を示したときに新しい過塩素酸マグネシウムと交換し た。試料空気採取口から LI-6252 までの採取パイプ (内 径 $0.006 \mathrm{~m}$ ) の長さは約 $15 \mathrm{~m}$, 採取流量は $400 \mathrm{ml}$ $\min ^{-1}$ である。除湿された試料空気の流路を 3 方電磁弁 を使って 3 分毎に切り替え, 交互に LI-6252 の測定セ ルに導入した。ガス流路の切り替え直後の 2 分間の LI6252 の信号は, 試料空気のサンプリング回路内のガス 置換に必要な時間の信号と考えて無視し, 最後の 1 分間 の信号の平均值を読み取った。読み取り值 5 個を平均し て二酸化炭素の 30 分平均值とした。

\section{2 デー夕選抜}

今回, われわれは二酸化炭素の無次元勾配の計算に使 用するデー夕を下の 2 段階で選抜した。

1) 摩擦速度を利用した選抜

Miyata (2001) は, 傾度法と渦相関法で求めたフラッ クスを比較し, 摩擦速度 $u_{*}$ が $0.05 \mathrm{~m} \mathrm{~s}^{-1}$ 未満の場合に
フラックスが大きく異なることを指摘している。われわ れあ Miyataに従い, $u_{*}<0.05 \mathrm{~m} \mathrm{~s}^{-1}$ の場合のデー夕を 排除した。

2) Monin-Obukhovの相似則を利用した選抜

Monin-Obukhov の相似則によると, 二酸化炭素の標 準偏差 $\sigma_{\mathrm{c}}$ を摩擦濃度 $c_{*}\left(=-\overline{w^{\prime} c^{\prime}} / u_{*}\right)$ で無次元化する 之, $\sigma_{\mathrm{c}} / \boldsymbol{c}_{*}$ が安定度パラメーターの普遍関数 $\boldsymbol{G}_{\mathrm{c}}$ と表され る。この $G_{\mathrm{c}}$ の值を利用して, 2 種類のデー夕選抜を行っ た。

a） $\left|G_{\mathrm{c}}\right|$ は不安定成層時 $(\zeta<0)$ には $\zeta^{-1 / 3}$ に比例して 減少し (Ohtaki, 1985), 安定成層時 $(\zeta \geq 0)$ には $\zeta^{1 / 3}$ に 比例して増加することが分かっている。この経験則に 従っている $\left|G_{\mathrm{c}}\right| \leq 10$ のデー夕を選抜した。逆に $\left|G_{\mathrm{c}}\right|>$ 10 の場合には, 二酸化炭素の密度変動が小さく, 測定限 界レベルの信号を扱うことになり, 意味のある議論とな らない恐れがある。

b）水稲の生育が著しい 8 9月には, 群落上の大気が 不安定成層 $(\zeta \leqq 0)$ を示すのは 7 時頃から 14 時頃まで で, 残りの時間帯は安定成層（ $\zeta \geqq 0 ）$ となっている。ま た, 二酸化炭素は 6 時過ぎから 18 時頃まで鉛直下向に 輸送され，その他の時間帯は鉛直上向に輸送されてい る。安定成層時にもかかわらず, $14 \sim 19$ 時の間は $G_{\mathrm{c}} \geq 0$ であり, 20 時〜翌朝 6 時の間は $G_{\mathrm{c}} \leqq 0$ である。同じよ うな状況は不安定時にも発生することがある。浮力と風 のシアーの項から決まる Monin-Obukhov の安定度パ ラメーターとを指標にして, それとは別の要因の影響む 
受ける二酸化炭素の変動特性をまとめる場合には, この 種の問題は避けられない。逆に，われわれは，MoninObukhov 相似則に不確かさが生じている 14〜19 時の 時間帯で, 熱と二酸化炭素の変動特性がどのような相違 を示すのかに注目している。あう少しデー夕を集めて， 相似性に関する成果をまとめたいと思っている。今回は 安定成層時 $(\zeta \geqq 0)$ に $G_{\mathrm{c}} \geqq 0$ となるデー夕, 不安定成層 時（ $\zeta \leqq 0 ） に G_{\mathrm{c}} \leqq 0$ となるデー夕は削除した。

以上，1），2）の選抜方法をクリアしたのは，全デー 夕 576 個の約 $63 \% ， 362$ 個であった。これらのデー夕 を使って二酸化炭素の無次元勾配の関数形を求めた。

\section{4. 結果と考察}

\section{1 二酸化炭素の無次元勾配 $\phi_{\mathrm{c}}$}

2002 年 9 月の晴天時に得られた二酸化炭素の無次元 勾配 $\phi_{\mathrm{c}}$ の值を Fig. 2 に示す。図の横軸は安定度パラ

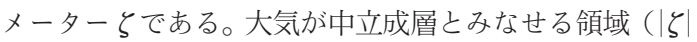
$<0.05 ） て ゙ は \phi_{\mathrm{c}}=1$ である。大気の不安定成層か強くな るにつれて $\phi_{\mathrm{c}}$ は小さくなり, 図中の実線 $\phi_{\mathrm{c}}=(1-8 \zeta)^{-1 / 2}$ で近似できる。他方, 安定成層のときには, プロット点 の乱れが大きいが， $\phi_{\mathrm{c}}=1+5 \zeta$ で近似できると考えた。 近似した関数形を下にま之めておく。

不安定成層 $(\zeta<0): \phi_{\mathrm{c}}=(1-8 \zeta)^{-1 / 2}$

安定成層 $(\zeta \geq 0): \phi_{\mathrm{c}}=1+5 \zeta$

$\phi_{\mathrm{c}}$ に関しては, Monji et al. (2002) の報告があるだけ である。彼らは, $\phi_{\mathrm{c}}$ を Businger et al. (1971) が温度の 無次元勾配に対して提案している関係式 $\left(\phi_{\mathrm{h}}\right)$ と比較 し, 不安定成層状態では両者は一致するが, 安定性成層 状態では両者の不一致が大きいことを示している。 $\phi_{\mathrm{c}}$ に 関する文献值がないので, Brutsaert (1982) にまとめら れている温度と水蒸気の無次元勾配 $\phi_{\mathrm{h}}$ と $\phi_{\mathrm{q}}$ の関数形
と比較してみる。一般的には， $\phi_{\mathrm{h}}$ と $\phi_{\mathrm{q}}$ の関数形は不安 定成層時には $\phi=A(1-B \zeta)^{-1 / 2}$, 安定成層時には $\phi=C$ $+D \zeta$ の形で表現される。不安定成層の場合には, $A$ は約 1 であり, $B$ は 8 と 16 の 2 系統に分かれる傾向がある。 今回われわれが示した関数形は, Businger et al. (1971) の $\phi_{\mathrm{h}}=0.84(1-7.9 \zeta)^{-1 / 2}$ と Smedman-Högström and Högström (1973) の $\phi_{\mathrm{q}}=(1-9 \zeta)^{-1 / 2}$ 之似ている。安定 成層時の報告例は少ないが, $C=1, D=5 \sim 7$ である。こ の上うな既出の $\phi_{\mathrm{h}}$ 之 $\phi_{\mathrm{q}}$ の特徵と比較すれば, 今回得ら れた $\phi_{\mathrm{c}}$ は， $\phi_{\mathrm{h}}$ や $\phi_{\mathrm{q}}$ と同じような安定度依存性を示して いるように思える。これは二酸化炭素の乱流変動特性 が，水蒸気や温度の変動特性之似ているという Ohtaki （1985）の報告とも整合している。

\section{2 傾度法と渦相関法による二酸化炭素フラックス}

(6)，（7）式で与えられた $\phi_{\mathrm{c}}$ の関数形を（4）式に代入 し積分すれば，(5）式の分母 $f(\zeta)$ の関数形が求まり, $F_{\mathrm{c}}($ aero) を計算することができる。 $f(\zeta)$ の関数形は大 気層の安定度によって, 以下の式で与えられる。

$$
\begin{gathered}
f(\zeta)=\ln \left|\frac{\left(\sqrt{1-8 \zeta_{2}}-1\right)\left(\sqrt{1-8 \zeta_{1}}+1\right)}{\left(\sqrt{1-8 \zeta_{2}}+1\right)\left(\sqrt{1-8 \zeta_{1}}-1\right)}\right| \\
\zeta<0 \\
f(\zeta)=\ln \left(\frac{\zeta_{2}}{\zeta_{1}}\right)+5\left(\zeta_{2}-\zeta_{1}\right) \quad \zeta \geq 0
\end{gathered}
$$

2002 年 9 月の快晴日のデー夕を使って計算した $F_{\mathrm{c}}($ aero $)$ と渦相関センサーで測定した $F_{\mathrm{c}}($ eddy) の值を Fig. 3 に示す。プロットされた值は乱れているが，1: 1 の線の周辺に分布している。 $\pm 20 \%$ の誤差を許せば, （6）（7）式に基づいた傾度法を実用に供することがで きる。

上の結果は, $\left(3^{\prime}\right)$ 式の右辺第 1 項の $F_{\mathrm{c}}(\mathrm{eddy})$ が欠測

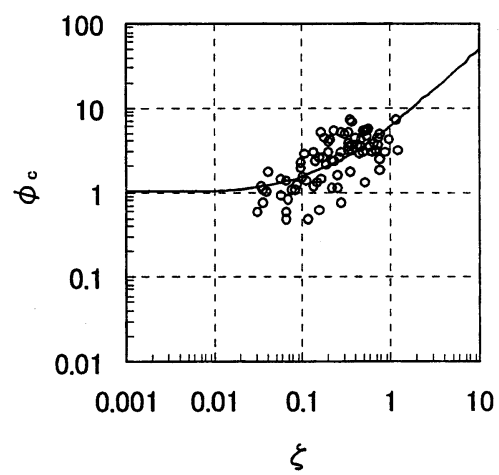

Fig. 2. Nondimensional gradient of carbon dioxide $\left(\phi_{c}\right)$ as a function of Monin-Obukhov stability parameter $\zeta$. 


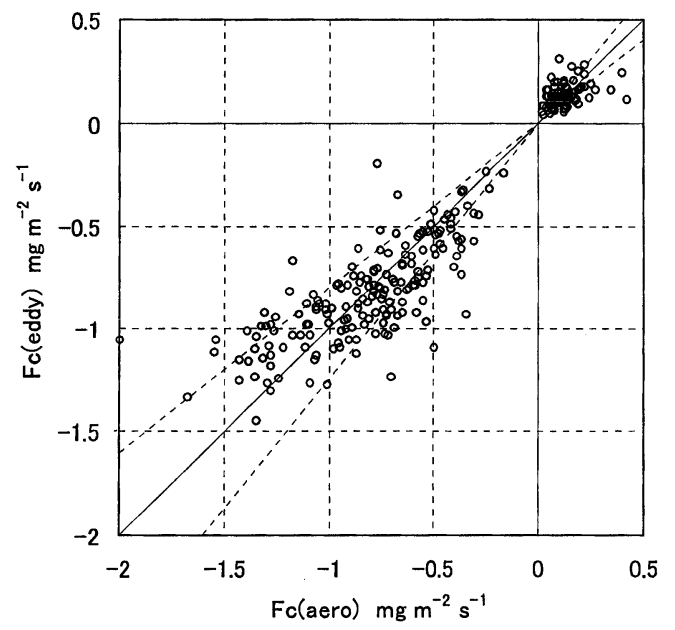

Fig. 3. Comparison between carbon dioxide fluxes obtained by the modified gradient technique, $F_{\mathrm{c}}$ (aero), and the eddy correlation technique, $F_{\mathrm{c}}$ (eddy). The solid line denotes 1: 1 correspondence, and dashed lines denote the discrepancies of $\pm 20 \%$ between both fluxes.

となったとき（5）式の $F_{\mathrm{c}}$ (aero）によってそれらの值 を補完することが可能であることを意味している。例と して, 2002年 9 月 26 30日（DOY: 269 273 日）の $F_{\mathrm{c}}$ (aero) と $F_{\mathrm{c}}$ (eddy) の日変化を Fig. 4 に示す。9 月 27 日 13 時頃から翌 28 日の 7 時頃まで連続した降雨が あった。9月 26 日と 29 日は曇天で, 9 月 30 日は晴天 であった。曇天と晴天日には, $F_{\mathrm{c}}($ aero $) と F_{\mathrm{c}}($ eddy) の 值はよく一致している。しかし, 降雨日には, 二酸化炭 素の渦相関法センサーは正常作動できず， $F_{\mathrm{c}}($ eddy) 大きく乱れ，測定不能を示している。これに対し， $F_{\mathrm{c}}$ (aero) は-0.3〜0.3 $\mathrm{mg} \mathrm{m}^{-2} \mathrm{~s}^{-1}$ の值を示している。 降雨時の $F_{\mathrm{c}}$ (aero) 值の正確さを検証することはできな いが，今回の結果は，降雨時には二酸化炭素が水稲群落 内外で等濃度になり，フラックスが小さくなるという以 前の観測結果と矛盾しない（Ohtaki and Seo, 1974）。

現在，二酸化炭素フラックスの測定は渦相関法に基づ いているが，センサーの動作不安定による欠測が避けら れない。特に 5 6月の梅雨期に欠測が多く， 水稲生育 初期の二酸化炭素フラックスの議論に苦慮することがあ る。今回提案した傾度法は, 渦相関法による欠測を少な くするための有力な方法である。あちろん, Webb et al. （1980）が提案した補正項を含む二酸化炭素のトータル フラックス $(\overline{w c})$ を把握するには, $\left(3^{\prime}\right)$ 式の右辺第 2 項 と第 3 項の值を測定しておく必要がある。残念ながら,

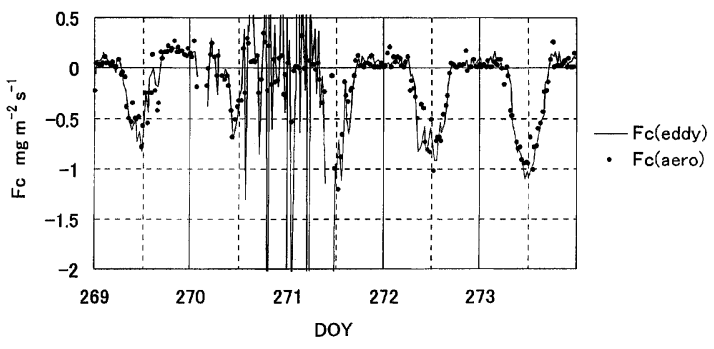

Fig. 4. Examples of diurnal variation of carbon dioxide measured by the modified gradient technique, $F_{\mathrm{c}}$ (aero), and the eddy correlation technique, $F_{\mathrm{c}}$ (eddy), during September 26 (DOY $=269)$ to September 30 (DOY=273), 2002.

雨天日には渦相関法で潜熱を測定することが困難なの で, 上と同じ要領で, 傾度法で潜熱之顕熱を求めて右辺 第 2 項と第 3 項の值を推定することになる。9 月 27〜 28 日の降雨期に, 傾度法で推定した右辺第 2 項と第 3 項の和は $-0.1 \sim 0.1 \mathrm{mg} \mathrm{m}^{-2} \mathrm{~s}^{-1}$ であった。雨天時には $\overline{w^{\prime} c^{\prime}}$ 項も顕熱と潜熱フラックスによる補正項も小さい のが現実である。したがって, 雨天日には, 顕熱之潜熱 フラックスによる補正項の割合が $\overline{w^{\prime} c^{\prime}}$ 項に対して大き くなることああるが，トータルな二酸化炭素フラックス 值が小さいので, $F_{\mathrm{c}}$ (aero) だけの補完でも深刻な影響は 無いと考えられる。

\section{5. まと め}

二酸化炭素の無次元勾配を測定し, 傾度法と渦相関法 による二酸化炭素フラックスの比較を行った。以下の成 果が得られた。

1）二酸化炭素の無次元勾配は以下の関数で表現でき る。

不安定成層時 $(\zeta<0): \phi_{\mathrm{c}}=(1-8 \zeta)^{-1 / 2}$

安定成層時 $\quad(\zeta \geq 0): \phi_{\mathrm{c}}=1+5 \zeta$

2) 晴天と曇天時には, 渦相関センサーで測定した $F_{\mathrm{c}}\left(\right.$ eddy) と傾度法で推定した $F_{\mathrm{c}}$ (aero) は一致す る。

3）降雨時においても， $F_{\mathrm{c}}$ (aero）は有意なフラックスを 提供する可能性がある。

4）二酸化炭素のトータルフラックス $(\overline{w c})$ を把握するに は, Webb et al.（1980）が指摘した顕熱之潜熱によ る補正項を別途測定しておく必要がある。実際には, 雨天日の顕熱之潜熱フラックスは小さいので，上の 補正項の影響は小さい。 


\section{謝辞 \\ 本研究の一部は科学研究費補助金 (13308027) を用い \\ て行われた。快く農場の使用を許可してくださった岡山 大学農学部八浜農場の多田正人主任に感謝します。}

\section{References}

Brutsaert, W., 1982: Evaporation into the atmosphere. D. Reidel Pub. Co., London, pp. 57-112.

Businger, J. A., Wyngaard, J.C., Izumi, Y. and Bradley, E.F., 1971: Flux-profile relationships in the atmospheric surface layer. J. Atmos. Sci., 28, $181-189$.

Dyer, A. J. and Hicks, B. B., 1970: Flux-gradient relationships in the constant flux layer. Quart. J. Roy. Meteorol. Soc., 96, 715-721.

Harazono, Y., Hirano, T., Saigusa, N., Ohtani, Y., Miyata, A., Ohtaki, E. and Monji, N., 2003: Roles of long-term flux observations as the global change study and the current topics. J. Agric. Meteorol., 59, 69-80 (in Japanese with English summary).

Harazono, Y., Monji, N., Miyata, A., Kita, K., Hamotani, K., Uchida, Y., Yoshimoto, M., Sano, T., Fujihara, M., Isobe, S. and Ogawa, T., 1996: Development of measurement methods for trace gas fluxes in the surface boundary layer and a basic examination of the flux evaluation. Bull. Nat. Inst. Agro-Environ. Sci., 13, 166-226 (in Japanese with English summary).

Miyata, A., 2001: Observational study on methane exchange between wetland ecosystems and the atmosphere. Bull. Nat. Inst. Agro-Environ. Sci., 19, 61-183.

Monji, N., 2003: Plants and micrometeorology-Turbulence and fluxes in plant atmosphere-. Osaka
Municipal Univ. Press, Osaka, 140 pp. (in Japanese).

Monji, N., Hamotani, K., Tosa, R., Fukagawa, T., Yabuki, K., Hirano, T., Jintana, V., Piriyayota, S., Nishimiya, A. and Iwasaki, M., 2002: $\mathbf{C O}_{2}$ and water vapor flux evaluations by modified gradient methods over a mangrove forest. J. Agric. Meteorol., 58, 63-69.

Ohtaki, E., 1984: Application of an infrared carbon dioxide and humidity instrument to studies of turbulent transport. Boundary-Layer Meteorol., 29, 85-107.

Ohtaki, E., 1985: On the similarity in atmospheric fluctuations of carbon dioxide, water vapor and temperature over vegetated fields. Boundary-Layer Meteorol., 32, 25-37.

Ohtaki, E. and Matsui, T., 1982: Infrared device for simultaneous measurement of fluctuations of atmospheric carbon dioxide and water vapor. Boundary-Layer Meteorol., 24, 109-119.

Ohtaki, E. and Seo, T., 1974: Measurement of gradient of carbon dioxide and estimation of its flux over a paddy field. (2) Observation at Hachihama in 1969. Ber. Ohara Inst. Landw. Biol. Okayama Univ. Bd., 16, 65-77.

Smedman-Högström, A.S. and Högström, U., 1973: The marsta micro-meteorological field project. Profile measurement system and some preliminary data. Boundary-Layer Meteorol., 5, 259-273.

Webb, E. K., Pearman, G. I. and Leuning, R., 1980: Correction of flux measurements for density effects due to heat and water vapor transfer. Quart. J. Roy. Meteorol. Soc., 106, 85-100.

Yamamoto, S., 1999: $\mathrm{CO}_{2}$ flux network based on tower measurements in forest ecosystems. Tenki, 46, 15-20 (in Japanese). 